\title{
Cultura preventiva en Hero España
}

\section{Prevention culture at Hero España}

\section{David Martín Naranjo'}

1. David Martín Naranjo, Responsable del Servicio de Prevención de Riesgos Laborales de Hero España, S.A.

\section{Correspondencia}

David Martín Naranjo

Responsable del Servicio de Prevención de Riesgos Laborales de Hero España, S.A. España.

Correo electrónico: david.martin@hero.es

Resumen

Presentación de una de las prácticas realizadas en materia de Seguridad y Salud en el Trabajo que se llevan a cabo en la Compañía, reseñable por su carácter innovador y alto grado de efectividad. Esta práctica va más allá del cumplimiento de lo legalmente establecido en el ámbito de la Prevención de Riesgos Laborales (PRL), y tienen como objetivo principal la participación en materia de PRL de todos los trabajadores de la Empresa, independientemente de su puesto o cargo.

Para que esta participación sea efectiva, y la implantación completa a todos los niveles, es necesario contar con la colaboración activa de los representantes de los trabajadores, en este caso los Delegados de Prevención.

Formación, información, inspecciones de seguridad, auditorías e implantación a todos los niveles de la política de PRL son pilares básicos para la existencia de una verdadera cultura preventiva en Hero España.

Palabras clave: cultura preventiva / formación / implantación / prevención.

Abstract:

Launch of a Safety and Health practice, done into the company, highlighted due to its innovative and effectivity. This practice overpasses, the working risk prevention law in force, having as a target the participation of all the staff of the company, regardless of positions.

It is essential to rely on all staff, Prevention managers in this case, for a effective participation and a complete establishment.

Training, information, safety inspections, audits and establishment are essential for the existence of a real preventive culture at Hero España

Key words: Preventive culture, training, establishment, prevention. 


\section{INTRODUCCIÓN}

Hero, fundada en 1886 en Lenzburg (Suiza), es una compañía internacional comprometida con ofrecer productos naturales y de calidad. Sería en 1922 cuando llega a España al constituir Hero Alcantarilla (Murcia), formando parte de su política de expansión internacional, que también le llevaría a abrir filiales en Italia y Holanda, a principios del siglo XX.

Los primeros pasos de Hero en España se centraron en transformar la excelente materia prima de la huerta murciana para abastecer a las empresas del Grupo, y poco a poca pasar a comercializar en el mercado español productos bajo la marca Hero, principalmente confituras y almíbares. En 1985 se produce un hito histórico: Hero España crea, produce y comercializa una nueva gama de productos de alimentación y nutrición infantil.

Desde su fundación, Hero España está comprometida con el cumplimiento estricto de requisitos de calidad externos e internos, que garantizan una trazabilidad completa de todos sus ingredientes, procesos y envases, como lo acreditan sus certificados de calidad.

El principio fundamental de la empresa es crear éxito a largo plazo, ser sostenibles y crear valor para la sociedad. Un valor añadido, cualitativo y cuantitativo a la competitividad, que está impreso en el ADN de la compañía e impregna el trabajo diario de sus empleados, actuando con integridad, lealtad, honestidad y dentro del marco legal.

Se ofrecen productos sanos, nutritivos y de alta calidad, mientras se aplican prácticas equitativas en materias Derechos Humanos y Laborales, Medio Ambiente y la lucha contra la corrupción, como se define en el Pacto Mundial de ONU y la Organización Internacional del Trabajo.

Para todo ello, Hero España cuenta con investigadores, científicos y expertos en nutrición que trabajan en la mejora de productos y procesos. La importancia de la innovación para la empresa se refleja en sus más de 1.500 referencias de productos.

\section{PRL EN LA EMPRESA}

Siendo conocedores de que para una correcta gestión de la prevención se deben establecer un conjunto de procedimientos y actuaciones que faciliten la identificación de riesgos y reducción de los mismos, en 1996 se publica el "El Plan de Prevención y Salud Laboral", documento en el que se establece la política de prevención de la empresa, se definen las funciones y responsabilidades y se describe el sistema de gestión de la prevención, orientando sobre las diferentes actividades preventivas a desarrollar y los documentos a utilizar.

El objetivo principal es conseguir el "cero accidentes laborales" mediante la eliminación de los riesgos derivados de las tareas que se realizan y el aumento del confort laboral de los trabajadores en sus puestos.

La Dirección de Hero España marca dentro de su Política Estratégica de Recursos Humanos, donde se establece como parte importante, la Gestión de Prevención Laboral para todos los niveles de la misma, y hace cumplir la Normativa de Prevención a todos los que, no teniendo relación laboral con la Empresa, tengan que realizar servicios en la misma.

Hero España es consciente de que para mantener una correcta gestión de la prevención se deben establecer un conjunto de procedimientos y actuaciones que faciliten la identificación de riesgos y reducción de los mismos. Para ello, en 1996 se publica el "El Plan de Prevención y Salud Laboral", documento en el que se establece la política de prevención de la empresa, se definen las funciones y responsabilidades, y se describe el 
sistema de gestión de la prevención, orientando sobre las diferentes actividades preventivas a desarrollar y los documentos a utilizar.

El objetivo principal es conseguir el "cero accidentes laborales" mediante la eliminación de los riesgos derivados de las tareas que se realizan y el aumento del confort laboral de los trabajadores en sus puestos.

La Dirección de Hero España marca dentro de su Política Estratégica de Recursos Humanos la Gestión de Prevención Laboral para todos los niveles de la misma, estableciéndolo como parte importante. Asimismo, se encarga de hacer cumplir la Normativa de Prevención a todos los que, no teniendo relación laboral con la Empresa, tengan que realizar servicios en la misma.

Actualmente se están llevando a cabo en Hero España una serie de Buenas Prácticas en materia de PRL, que tanto por el impacto positivo en nuestra Compañía, como en el entorno y empresas con las que trabajamos, merecen ser destacadas: Sesión Formativa ADAPTRA y las Instrucciones de Trabajo Seguro.

\section{Sesión formativa ADAPTRA (Adaptación al Puesto de Trabajo)}

Durante el proceso de incorporación de un nuevo trabajador, el primer paso es recibir formación e información específica en la prevención de riesgos en los puestos que va a por parte del Servicio de PRL de Hero.

En un primer momento, se comprobó que esta formación era suficiente y contaba con un amplio material de apoyo (diverso material como videos personalizados de las secciones, manuales específicos, test de control de conocimientos), pero en su afán de ir más allá en cuanto a la seguridad de los trabajadores, la compañía se planteó complementar esta formación con una sesión de adaptación al puesto de trabajo impartida por el responsable directo del trabajador y en el propio puesto de trabajo.

Esta sesión se denomina ADAPTRA (Adaptación al Puesto de Trabajo) y es eminentemente práctica (se lleva a cabo frente al equipo de trabajo y en la planta de producción). Para su correcto desarrollo, el responsable dispone de una copia de la evaluación de riesgos del puesto de trabajo (que previamente ha llevado a cabo el Servicio de Prevención), además de su propia experiencia, para explicar al nuevo trabajador como realizar sus tareas de forma segura. Esta sesión de adaptación al puesto de trabajo queda registrada y firmada por el responsable y el empleado, de manera que se dispone de una base de datos real y actualizada de las personas que han recibido la sesión ADAPTRA.

Se trata de una medida con la que prevenir diferente situaciones que se han observado:

- Un trabajador que ha recibido toda la formación e información necesaria puede encontrarse al llegar a su puesto de trabajo con la necesidad de recibir más apoyo en materia de seguridad.

- El trabajador que se incorpora puede pensar que los únicos encargados/ responsables de la seguridad y salud de los trabajadores son los miembros del servicio de prevención.

- El trabajador no llega a establecer con su responsable directo una relación basada en la cultura preventiva y en la posibilidad de transmitir posibles mejoras en la seguridad y salud.

- No integración de la prevención y las políticas en esta materia en todo el organigrama jerárquico de la compañía.

\section{Instrucciones de trabajo seguro}

Uno de los principales factores de riesgo en la industria agroalimentaria es la diversidad de procesos y la continua interacción de los trabajadores con los equipos de trabajo, en los que deben preparar la materia prima de los procesos hasta su envasado o 
procesado final. También deben pasar por los continuos cambios de formatos y limpieza de los equipos e instalaciones.

Esta interacción hace que puedan surjan ciertos riesgos:

- Atrapamientos o golpes con elementos móviles de los equipos de trabajo, durante los procesos productivos y/o la limpieza de los mismos.

- Contactos térmicos con superficies que por motivos de producción deben alcanzar temperaturas elevadas. Aunque todas las superficies que alcanzan altas temperaturas se encuentran calorifugadas el riesgo está presente.

- Cortes por objetos o herramientas empleadas. En ocasiones el proceso productivo necesita del uso de herramientas manuales.

Aunque todos los trabajadores han recibido formación e información y conocen los riesgos de los equipos de trabajo, en Hero España se apuesta por incrementar de forma permanente la información acerca de la manipulación segura de equipos de trabajo. Para ello, además de la formación ADAPTRA, cada empleado y su responsable desarrollan una ficha con los principales riesgos de cada equipo de trabajo, incluyendo fotografías de los puntos más importantes del equipo. Estas fichas (o Instrucciones de Trabajo Seguro, ITS) incluyen las medidas preventivas, recomendaciones y EPI's necesarios en el equipo de trabajo.

Estas ITS son impresas y colocadas en cada equipo de trabajo junto al operario, para que siempre tenga presente las recomendaciones más importantes para un trabajo seguro.

Como resultados de la aplicación y puesta en marcha de estas dos Buenas Prácticas podemos destacar:

- Reducción a cero del número de accidentes provocados por el desconocimiento de las medidas de seguridad que deben cumplirse en el puesto de trabajo, así como en la manipulación de los equipos.

- Se resuelven las dudas que le surgen al trabajador en el momento de ponerse frente al equipo de trabajo.

- Incentiva y promociona la cultura preventiva, tanto en los trabajadores que reciben la sesión como en el responsable que la imparte, dando a ambos la posibilidad de participar en la gestión de ser la seguridad y salud en la compañía.

- El proceso de ADAPTRA es auditado en planta periódicamente por los delegados de prevención de la compañía, así como por el servicio de prevención propio de Hero España.

- Fomento la participación de los trabajadores en la seguridad en los equipos de trabajo, ya que se les consulta directamente sobre la realización y contenido de las ITS.

- La información contenida en las instrucciones de trabajo seguro complementan y refuerzan a diario los conocimientos sobre los riesgos de los equipos de trabajo y la manera de prevenirlos en los trabajadores que los manipulan. 